\title{
Mineral bone disorder and osteoporosis in hemodialysis patients
}

\author{
Maroua Slouma ${ }^{\text {* }}$, Hela Sahli ${ }^{2}$, Afef Bahlous ${ }^{3}$, Lilia Laadhar ${ }^{4}$, Wided Smaoui ${ }^{5}$, Sonia Rekik ${ }^{2}$, Imen Gharsallah', \\ Meriem Sallami ${ }^{4}$, Fatma Ben Moussa ${ }^{5}$, Mohamed Elleuch ${ }^{2}$ and Elhem Cheour ${ }^{2}$
}

\begin{abstract}
Background: Bone disease is common in patients undergoing hemodialysis. It is the result of bone turnover abnormalities and the decrease of bone mineral density (BMD). We aimed to determine the usefulness of serum bone turnover markers and BMD measurement by dual-energy $x$-ray absorptiometry (DXA) in hemodialysis patients.

Methods: We conducted a cross-sectional study including 90 hemodialysis for more than 12 months. Bone mineral density was assessed by DXA. Peripheral blood samples were obtained from each patient before dialysis in a fasting state within a week of the DXA. Biochemical variables of calcium and phosphate were measured. One bone formation marker (bone-specific alkaline phosphatase (bAP), one bone resorption marker (carboxy-terminal telopeptides of type 1 collagen (CTX)) were measured. Total alkaline phosphatase (TAP), intact parathyroid hormone (PTH) and fibroblast growth factor 23 (FGF23) which is a bone-derived hormone were also measured.
\end{abstract}

Results: CTX values were 6.25 times higher than the normal limit of the assay. Bone alkaline phosphatase levels were less than $10 \mathrm{ng} / \mathrm{mL}$ in $28.8 \%$ of cases. $23 \%$ of patients have osteoporosis and $45 \%$ have osteopenia.

Femoral BMD had negative correlations with age and PTH levels. FGF23 levels were significantly increased in patients with osteoporosis affecting the lumbar. The levels of bAP and CTX showed a positive correlation. Both circulating bAP and CTX levels showed also positive correlations with PTH levels. Fractures, observed in $12.2 \%$ of cases, were associated with low PTH values and the existence of osteoporosis.

Conclusions: Our study showed that osteoporosis and fracture are common in dialysis patients. The reduced BMD was associated with advanced age and elevated levels of PTH. Markers of bone turnover and FGF23 may play a role in the diagnosis of bone disease in hemodialysis patients. DXA measurement is necessary for the monitoring for bone loss.

Keywords: Osteoporosis, Hemodialysis, Fracture, Bone mineral density, Fibroblast growth factor 23, Bone specific alkaline phosphatase, Carboxy-terminal telopeptide of type 1 collagen

\section{Background}

Bone disease is highly prevalent in patients with chronic kidney disease on dialysis (CKD-5D) [1]. It can induce serious bone health problems, especially fragility fractures. Bone disease in patients with CKD-5D is the result of bone turnover abnormalities and the decrease of bone mineral density (BMD). Bone biopsy remains the gold standard for the diagnosis of bone turnover abnormalities. However, it is an invasive method and repetitive assessment of bone status cannot be possible. Measurements of

\footnotetext{
* Correspondence: maroua.slouma@gmail.com

'Department of Internal Medicine, Military Hospital, Tunis El Manar University, 1007 Tunis, Tunisia

Full list of author information is available at the end of the article
}

serum bone turnover markers are not common practice in the management of CKD-5D patients [1]. Fibroblast growth factor-23 (FGF23) is a circulating factor produced by osteocytes. This hormone inhibits phosphate reabsorption and renal production of $1,25(\mathrm{OH})$ vitamin D. FGF23 regulates phosphate and vitamin $\mathrm{D}$. This hormone plays an important role in bone metabolism of patients with chronic kidney disease [2]. Moreover, the assessment of bone mass in patients under dialysis is not yet codified. Both bone resorption and bone formation markers in patients with CKD-5D may be up- or down-regulated by systemic hormones such as parathormone. The measurement of BMD by dual-energy $x$-ray absorptiometry (DXA) is recommended only in patients with a history of

(C) The Author(s). 2020 Open Access This article is distributed under the terms of the Creative Commons Attribution 4.0 International License (http://creativecommons.org/licenses/by/4.0/), which permits unrestricted use, distribution, and 
fractures. Multiple factors are associated with reduced BMD and may affect bone health [3].

This study aimed to determine the usefulness of serum bone turnover markers by measuring one bone formation marker (bone-specific alkaline phosphatase) and one bone resorption marker (carboxy-terminal telopeptides of type 1 collagen) and the usefulness of the BMD by DXA in patients with CKD-5D. We aimed also to assess the frequency and risk factors of osteoporosis and osteoporotic fracture in hemodialysis patients.

\section{Methods}

\section{Patients}

We conducted a cross-sectional study including patients in maintenance hemodialysis three times weekly for more than 12 months.

Exclusion criteria included patients younger than 20 years, premature menopause (occurring before the age of 40), prolonged immobilization and patients receiving treatments related to mineral metabolism (long-term steroids, hormone replacement therapy, and bisphosphonate). Patients with a history of gastrectomy, parathyroidectomy, neoplasia or hysterectomy were excluded from this study. Patients with disease that may affect bone such as chronic inflammatory bowel disease, cirrhosis, and endocrinopathies except diabetes were also excluded.

Demographic and clinical data, including age, gender, anthropometric measurements, body mass index (weight $/$ height $^{2}$ ), comorbidities, menopausal status, etiology of kidney disease, and duration of dialysis were collected. We inquired also about low trauma fractures since starting dialysis.

\section{Measurements of biochemical variables}

Peripheral blood samples were obtained from each patient before dialysis in a fasting state within a week of the DXA. Biochemical variables of calcium and phosphate were measured using an in vitro photometric assay for automated clinical chemistry analyzers.

Plasma intact PTH (PTH) levels were measured using chemiluminescent microparticle immunoassay. Normal values range from $15-65 \mathrm{pg} / \mathrm{mL}$.

Serum concentrations of $25(\mathrm{OH})$ vitamin D $(25(\mathrm{OH}) \mathrm{D})$ were measured using chemiluminescent immunoassay. Vitamin D deficiency was defined as $25(\mathrm{OH}) \mathrm{D}$ values lower than $10 \mathrm{ng} / \mathrm{mL}$, vitamin D insufficiency was defined as $25(\mathrm{OH}) \mathrm{D}$ values between 10 and $30 \mathrm{ng} / \mathrm{mL}$ [4]. Recommended rates of vitamin $\mathrm{D}$ ranged between 30 and $70 \mathrm{ng} / \mathrm{mL}$.

Bone alkaline phosphatase (bAP), a marker of osteoblastic activity, was measured using an immunosorbent enzyme-linked assay.
C-terminal telopeptide of type I collagen (CTX), a marker of osteoclastic activity, was measured by chemiluminescent immunoassay.

Fibroblast growth factor 23 (FGF23) was measured with the ELISA technique. Normal values range from 30 to $176 \mathrm{pg} / \mathrm{mL}$.

\section{Measurements of BMD}

Dual-energy X-ray absorptiometry (DXA) was performed to assess bone mineral density (BMD). Instrument quality control was performed regularly. Bone mass density, expressed in $\mathrm{gm} / \mathrm{cm}^{2}$, was measured at the lumbar spine, total hip, femoral neck, and total body.

In the lack of diagnostic criteria for defining osteoporosis in men and premenopausal women, we used WHO criteria as a cutoff point. Osteopenia corresponded to Tscore more than $-2.5 \mathrm{SD}$ but less than $-1 \mathrm{SD}$. Osteoporosis was defined as T-score less than or equal to $-2.5 \mathrm{SD}$ in at least one of these sites: lumbar spine, femoral neck or total hip [5].

\section{Fragility fractures}

Fragility fractures were defined as fractures resulting from low-trauma (fall from standing-height or lower).

Lateral dorsal and lumbar spine X-rays were performed to assess vertebral fracture.

\section{Statistical analysis}

Statistical Package for Social Sciences (SPSS) version 19.0 was used to perform statistical analysis. Means and standard errors were calculated. Comparisons were performed using Student's $t$-test and analysis of variance (ANOVA) for normally distributed variables. The chisquare test was used to analyze categorical data. The multiple linear regression was performed to identify predictors of low bone mass. The significance level was set at $<0.05$. Correlations were reported as either the Pearson correlation coefficient.

\section{Results}

\section{Patients' characteristics}

A total of 90 patients were included in the study. All of them were Caucasian. There were 58 men $(64 \%)$ with a sex ratio of 1.8 . The mean age was 53.01 years $[20 ; 89]$. Sixty-eight percent of patients were under the age of 50 years. There were 8 post-menopausal women. The duration of hemodialysis was less than 5 years in $61 \%$ of patients whereas it was more than 10 years in only two cases. The calcium intake was noted in $97 \%$ of cases with a mean dose of $1.89 \mathrm{~g}$ daily [0.5; 3]. Only $30 \%$ of patients were orally supplemented with 0.5 microg of alfacalcidol daily.

Hyperphosphatemia was noted in $62.22 \%$ and hypocalcemia was found also in $62.22 \%$. Fifty-six percent of 
patients have PTH values between 2 and 9 times the upper normal limit of the assay. However, $19 \%$ of patients have PTH values less than 2 times the upper normal limit of the assay. Insufficiency and deficiency of vitamin D were found respectively in 41.11 and $44.44 \%$ of cases. CTX values were 6.25 times higher than the normal limit of the assay.

Only 6 patients had CTX levels within the normal range. Bone alkaline phosphatase levels were less than $10 \mathrm{ng} / \mathrm{mL}$ in 26 cases and higher than $25 \mathrm{ng} / \mathrm{mL}$ in 31 cases. Table 1 summarized the clinical and biological characteristics of patients.

\section{Prevalence of osteoporotic fracture}

Osteoporotic fractures were noted in $12.22 \%$ of cases $(n=11)$ and had occurred after the age of 50 years in 9 cases. Vertebral fractures are the most common type of osteoporotic fractures, found in 6 patients, followed by hip fractures noted in 3 cases. For the two other cases, there were wrist fracture and tibial fracture.

Table 1 Clinical and biological characteristics of patients

\begin{tabular}{|c|c|c|}
\hline \multicolumn{2}{|c|}{ Age, mean $\pm S D$ yesars } & $53.01 \pm 14.66$ \\
\hline \multicolumn{2}{|c|}{ Height, mean \pm SD cm } & $162.78 \pm 9.77$ \\
\hline \multicolumn{2}{|c|}{ Weight, mean \pm SD Kg } & $68.33 \pm 13.48$ \\
\hline \multicolumn{2}{|c|}{ Body mass index, mean $\pm \mathrm{SD} \mathrm{kg} / \mathrm{m}^{2}$} & $25.79 \pm 4.67$ \\
\hline \multicolumn{2}{|l|}{ Smoking (n (\%)) } & $50(55.5)$ \\
\hline \multicolumn{2}{|c|}{ Adequate exposure to sunlight (n (\%)) } & $55(61)$ \\
\hline \multirow[t]{3}{*}{ Comorbidities } & Diabetes (n (\%)) & $38(42)$ \\
\hline & Hypertension (n (\%)) & $60(66)$ \\
\hline & Dyslipidemia & $12(13)$ \\
\hline \multicolumn{2}{|c|}{ Duration of dialysis, mean \pm SD years } & $3.94 \pm 1.99$ \\
\hline \multirow[t]{6}{*}{ Causes of CKD } & Diabetic nephropathy (n (\%)) & $30(33.3)$ \\
\hline & Vascular nephropathy (n (\%)) & $6(6.6)$ \\
\hline & Glomerulonephritis (n (\%)) & $40(44.5)$ \\
\hline & Amyloidosis (n (\%)) & $1(1.2)$ \\
\hline & Polycystic kidney disease (n (\%)) & $4(4.4)$ \\
\hline & Tubulointerstitial nephropathy (n (\%)) & $9(10)$ \\
\hline \multicolumn{2}{|c|}{ Calcium (2-2.25 mmo/L) } & $2.08 \pm 0.32$ \\
\hline \multicolumn{2}{|c|}{ Phosphate (2-2.25 mmo/L) } & $1.84 \pm 0.57$ \\
\hline \multicolumn{2}{|c|}{ Albumin (30-45 mmom/L) } & $35.45 \pm 5.64$ \\
\hline \multicolumn{2}{|c|}{ Total alkaline phosphatase (60-220 U/L) } & $88.35 \pm 72.56$ \\
\hline \multicolumn{2}{|c|}{ PTH (12-65 pgmL) } & $425.7 \pm 380.8$ \\
\hline \multicolumn{2}{|c|}{$25 \mathrm{OH}$-vitamin D (ng/L) } & $15.76 \pm 11.58$ \\
\hline \multicolumn{2}{|l|}{ bAP (ng/mL) } & $26.84 \pm 26.99$ \\
\hline \multicolumn{2}{|l|}{$\mathrm{CTX}(\mathrm{ng} / \mathrm{mL})$} & $2.49 \pm 1.51$ \\
\hline \multicolumn{2}{|l|}{ FGF $23(\mathrm{pg} / \mathrm{mL})$} & $221.87 \pm 248.96$ \\
\hline
\end{tabular}

Data are presented as mean \pm standard deviation, $C K D$ Chronic kidney disease PTH Parathyroid hormone, bAP bone alkaline phosphatase, CTX C-terminal telopeptide of type I collagen, FGF 23 Fibroblast growth factor 23

\section{Prevalence of osteoporosis}

As shown in Table 2, osteoporosis was common among patients undergoing hemodialysis. $23 \%$ of patients have osteoporosis and $45 \%$ have osteopenia. Osteoporosis affected the hip more than the spine.

\section{Correlation between biological parameters}

There was a positive correlation between bAP and CTX. Moreover, both bone markers showed positive correlations with serum PTH levels. Table 3 demonstrated correlations between biological parameters.

\section{Associated factors of BMD}

As illustrated in Table 4, patients with osteoporosis were older than patients without osteoporosis. Men had higher DXA BMD than women at only the total body $\left(1.160 \pm 0.141\right.$ vs $\left.1.053 \pm 0.105 \mathrm{~g} / \mathrm{cm}^{2}, p<10^{-3}\right)$.

The mean BMD was significantly lower among patients with a history of diabetes at the total hip femoral $(0.894 \pm 0.162$ in patients with diabetes vs. $0.894 \pm 0.162$ in patients without diabetes, p: 0.003). Diabetic nephropathy was the most common etiology associated with decreased BMD at the femoral site whereas patients with polycystic kidney disease tended to have higher BMD than the other patients $\left(0.789 \pm 0.118 \mathrm{~g} / \mathrm{cm}^{2}\right.$ in patient with diabetic nephropathy vs. $0.980 \pm 0.249$ in patient with polycystic kidney disease, p: 0.031).

Parathyroid hormone levels were significantly increased in patients with osteoporosis affecting the total hip. Fibroblast growth factor 23 levels were significantly increased in patients with osteoporosis affecting the lumbar. However, vitamin D levels did not differ significantly between patients with and without osteoporosis.

The Pearson's correlations between clinical, anthropometric, biological and BMD were presented in Table 5.

As shown in Table 6, age and PTH levels significantly predicted the total hip BMD.

\section{Associated factors of fractures}

As demonstrated in Table 7, PTH levels were significantly lower in patients with fractures. Besides, patients with osteoporosis had more osteoporotic fractures than patients without osteoporosis.

\section{Discussion}

Patients with chronic kidney disease on dialysis (CKD5D) are at increased risk of osteoporosis and fractures than the general population [6]. In this bone DXA densitometry-based study, we detected that osteoporosis was common in dialysis patients, observed in $23 \%$ of cases. Indeed, literature data showed that the prevalence of osteoporosis varied from 4 to $47 \%$ at the lumbar spine and from 10 to $64 \%$ at the femoral site [7-15]. Moreover, Avramovski et al. [16] demonstrated that the 
Table 2 Results of bone mass in hemodialysis patients

\begin{tabular}{|c|c|c|c|c|c|c|}
\hline & \multirow[t]{2}{*}{$\mathrm{BMD}\left(\mathrm{g} / \mathrm{cm}^{2}\right)$} & \multirow[t]{2}{*}{ T-score (SD) } & \multicolumn{2}{|c|}{ Osteopenia } & \multicolumn{2}{|c|}{ Osteoporosis } \\
\hline & & & $\mathrm{N}$ & $\%$ & $\mathrm{~N}$ & $\%$ \\
\hline Lumbar spine & $1.156 \pm 0.218$ & $-0.465 \pm 1.748$ & 30 & 33 & 8 & 9 \\
\hline Total hip & $0.854 \pm 0.152$ & $-1.44 \pm 1.14$ & 40 & 44 & 18 & 20 \\
\hline Femoral Neck & $0.877 \pm 0.150$ & $-1.3 \pm 1.15$ & 45 & 50 & 12 & 13.33 \\
\hline Overall & - & - & 42 & 45 & 18 & 23 \\
\hline
\end{tabular}

$B M D$ Bone mineral density, SD Standard deviation, $N$ Number, \%: percentage

progression of bone mass loss was significantly greater in chronic hemodialysis patients than in general population patients. Using DXA assessment, Sit D et al. [13] showed that the lumbar spine was the region with the highest prevalence of osteoporosis. However, other studies are consistent with our study showing that osteoporosis affected the total hip (20\%) more than the lumbar spine (9\%). DXA technology can overestimate the BMD measured in the lumbar because of the existence of osteophytes and aortic calcification, frequently observed in hemodialysis patients [17].

Bone mass loss is considered as the consequence of several factors in hemodialysis patients. Several studies are consistent with our study showing that BMD decreased as age increased [14, 17, 18]. The effect of gender on bone mass in hemodialysis is controversial $[19,20]$. We found that BMD was significantly lower in women at the total body. The impact of diabetes on BMD is not yet clear. According to the study of Elder et al., we found that BMD at total hip was lower among dialysis patients with diabetes [21].

Chronic kidney disease is associated with hyperphosphatemia and hypocalcemia, observed in $62.22 \%$ in our patients, and induce secondary hyperparathyroidism. Fifty-six percent of patients have PTH values between 2 and 9 times the upper normal limit of the assay as recommended by KDIGO [1]. Observational studies demonstrated that PTH values at the extremes (lower than 2 times and more than 9 times) are associated with an increased relative risk of death in dialysis patients.

Table 3 Pearson's correlation between biological parameters

\begin{tabular}{llllll}
\hline & TAP & Vitamin D & PTH & bAP & CTX \\
\hline TAP & - & $-0.234^{*}$ & $0.430^{* * *}$ & $0.850^{* * *}$ & $0.558^{* * *}$ \\
Vitamin D & $-0.234^{*}$ & - & -0.121 & -0.212 & -0.089 \\
PTH & $0.430^{* * *}$ & -0.121 & - & $0.559^{* * *}$ & $0.578^{* * *}$ \\
bAP & $0.850^{* * *}$ & -0.212 & $0.559^{* * *}$ & - & $0.701^{* * *}$ \\
CTX & $0.558^{* * *}$ & -0.089 & $0.578^{* * *}$ & $0.701^{* * *}$ & - \\
FGF 23 & 0.062 & $0.247^{*}$ & -0.169 & -0.642 & -0.058
\end{tabular}

Date are presented as the $r$ value in Pearson's correlation test * $p<0.05$, ** $p<0.01,{ }^{* * *} p<0.001$. TAP Total alkaline phosphatase, PTH Parathyroid hormone, $b A P$ bone alkaline phosphatase, CTX C-terminal telopeptide of type I collagen, FGF 23 Fibroblast growth factor 23
Table 4 Comparison of clinical and biological characteristics between patients with and without osteoporosis

\begin{tabular}{|c|c|c|c|c|}
\hline & Normal & Osteopenia & Osteoporosis & $p$ \\
\hline \multicolumn{5}{|l|}{ Age (years) } \\
\hline Lumbar & $52.03 \pm 14.18$ & $52.55 \pm 14.26$ & $65.87 \pm 10.07$ & 0.034 \\
\hline Total hip & $49.58 \pm 15.02$ & $51.71 \pm 12.86$ & $63.94 \pm 11.39$ & 0.001 \\
\hline All & $50.06 \pm 15.09$ & $50.42 \pm 13.50$ & $63.94 \pm 11.39$ & 0.001 \\
\hline \multicolumn{5}{|c|}{ Age of onset of HD (years) } \\
\hline Lumbar & $49.33 \pm 14.42$ & $49.03 \pm 14.57$ & $63.37 \pm 10.02$ & 0.031 \\
\hline Total hip & $50.06 \pm 15.09$ & $48.84 \pm 13.58$ & $60.5 \pm 11.64$ & 0.001 \\
\hline All & $46.87 \pm 14.71$ & $48.21 \pm 14.16$ & $63.85 \pm 14.82$ & $<10^{-3}$ \\
\hline
\end{tabular}

PTH $(p g / m L)$

Lumbar $\quad 410.67 \pm 402.97 \quad 496.15 \pm 385.55 \quad 430.16 \pm 383.98 \quad 0.425$

Total hip $\quad 265.87 \pm 237.20 \quad 518.56 \pm 420.46 \quad 512.46 \pm 426.62 \quad 0.013$

$\begin{array}{lllll}\text { All } & 249.01 \pm 217.38 & 516.89 \pm 414.78 & 512.46 \pm 426.62 & \mathbf{0 . 0 0 6}\end{array}$

Vitamin D $(\mathrm{ng} / \mathrm{mL})$

$\begin{array}{lllll}\text { Lumbar } & 14.29 \pm 10.50 & 19.00 \pm 13.44 & 15.76 \pm 11.68 & 0.185 \\ \text { Total hip } & 16.61 \pm 10.71 & 16.28 \pm 11.38 & 13.25 \pm 14.03 & 0.59 \\ \text { All } & 16.80 \pm 10.74 & 16.11 \pm 11.13 & 13.25 \pm 14.03 & 0.576\end{array}$

$\mathrm{CTX}(\mathrm{ng} / \mathrm{mL})$

$\begin{array}{lllll}\text { Lumbar } & 2.50 \pm 1.58 & 2.60 \pm 1.46 & 1.85 \pm 1.06 & 0.45 \\ \text { Total hip } & 2.41 \pm 1.51 & 2.57 \pm 1.55 & 2.38 \pm 1.46 & 0.84 \\ \text { All } & 2.25 \pm 1.36 & 2.71 \pm 1.64 & 2.38 \pm 1.46 & 0.43\end{array}$

$\operatorname{bAP}(n g / m L)$

$\begin{array}{lllll}\text { Lumbar } & 25.23 \pm 27.27 & 30.99 \pm 30.22 & 20.77 \pm 9.41 & 0.54 \\ \text { Total hip } & 22.80 \pm 25.93 & 29.18 \pm 30.26 & 27.51 \pm 22.18 & 0.67 \\ \text { All } & 19.48 \pm 19.73 & 31.33 \pm 32.08 & 27.51 \pm 22.18 & 0.21\end{array}$

FGF $23(\mathrm{pg} / \mathrm{mL})$

$\begin{array}{llll}\text { Lumbar } & 192.90 \pm 242.32 & 194.50 \pm 229.21 & 428.13 \pm 275.64 \quad \mathbf{0 . 0 3 9}\end{array}$

$\begin{array}{llll}\text { Total hip } \quad 203.32 \pm 203.32 & 278.28 \pm 278.28 & 250.28 \pm 250.28 & 0.731\end{array}$

$\begin{array}{lllll}\text { All } & 185.37 \pm 203.32 & 229.46 \pm 278.28 & 240.43 \pm 250.28 & 0.731\end{array}$

HD Hemodialysis, PTH Parathyroid hormone, bAP bone alkaline phosphatase, CTX C-terminal telopeptide of type I collagen, FGF 23 Fibroblast growth factor 23

Significant at $p<0.05$ set in boldface 
Table 5 Pearson's correlation between clinical, anthropometric, biological and BMD

\begin{tabular}{llllll}
\hline & BMD L & BMD TH & BMD FN & BMD FA & BMD TB \\
\hline Age & -0.134 & $-0.289^{* *}$ & $-0212^{*}$ & $-0.290^{* *}$ & -0.190 \\
Duration of dialysis & 0.072 & -0.021 & -0.060 & 0.016 & -0.121 \\
BMI & 0.073 & -0.082 & -0.020 & -0.095 & 0.014 \\
Albumin & 0.057 & -0.05 & -0.111 & -0.131 & -0.027 \\
TAP & -0.083 & -0.144 & -0.109 & $-0.294^{* *}$ & $-0.277^{* *}$ \\
PTH & -0.140 & $-0.275^{* *}$ & $-0.232^{*}$ & $-0.326^{* *}$ & $-0.343^{* * *}$ \\
Vitamin D & -0.004 & $0.239^{*}$ & $0.216^{*}$ & 0.142 & 0.091 \\
bAP & -0.122 & -0.176 & 0.182 & $-0.299^{* *}$ & $-0.353^{* * *}$ \\
CTX & 0.022 & -0.055 & -0.071 & $-0.260^{*}$ & -0.206 \\
FGF 23 & -0.670 & -0.149 & -0.780 & -0.054 & -0.08 \\
\hline
\end{tabular}

Date are presented as the $r$ value in Pearson's correlation test $*<0.05$, ${ }^{* *}$ $p<0.01,{ }^{* * *} p<0.001$. BMD Body mass density, $L$ Lumbar spine, $T H$ Total hip, FN Femoral Neck, FA Forearms, TB Total Body, PTH Parathyroid hormone, bAP bone alkaline phosphatase, CTX C-terminal telopeptide of type I collagen, FGF 23 Fibroblast growth factor 23

Nevertheless, until now, there is no reference range of PTH values corresponding with normal bone turnover [22]. As in our study, Taal et al. [7] showed that the total hip BMD had a negative correlation with PTH. Besides, TAP correlated negatively with BMD in the total body. We didn't find an association between the serum albumin level and BMD. Even if Huang et al. [23] found a positive correlation between serum albumin levels and femoral neck BMD in dialysis patients. Lai et al. [24] showed that there was no relationship between these parameters.

Even if CTX is cleared by the kidney, our study showed that circulating bAP and CTX levels are correlated with serum PTH levels. Serum CTX levels have been found to predict bone loss in patients under dialysis $[25,26]$. Several studies have also demonstrated that

Table 6 Predicting models of total hip BMD and total body BMD

\begin{tabular}{lllll}
\hline Model & Standardized coefficients $\beta$ & $P$ & Total $R^{2}$ & $P$ \\
\hline TH BMD & & & & \\
Age & -0.337 & 0.001 & & \\
Vitamin D & 0.079 & 0.00 & 0.238 & $<10^{-3}$ \\
PTH & -0.307 & 0.002 & & \\
FA BMD & & & & \\
Age & -0.426 & 0.000 & 0.268 & $<10^{-3}$ \\
TAP & -0.248 & 0.213 & & \\
bAP & 0.89 & 0.375 & & \\
PTH & -0.118 & -0.916 & & \\
CTX & -0.271 & 0.093 & & \\
\hline
\end{tabular}

BMD Body mass density, TH Total hip, FA Forearms, PTH Parathyroid hormone, TAP Total bone alkaline phosphatase, bAP bone alkaline phosphatase, CTX Cterminal telopeptide of type I collagen
Table 7 Comparison between patients with and without osteoporotic fractures

\begin{tabular}{|c|c|c|c|}
\hline & \multicolumn{2}{|l|}{ Fracture } & \multirow[b]{2}{*}{$P$} \\
\hline & $\overline{\mathrm{No}}$ & Yes & \\
\hline Age (ans) & $51.94 \pm 14.53$ & $60.63 \pm 13.33$ & 0.06 \\
\hline BMI $\left(\mathrm{kg} / \mathrm{m}^{2}\right)$ & $25.76 \pm 4.43$ & $26.05 \pm 6.40$ & 0.84 \\
\hline $\mathrm{Ca}(\mathrm{mmol} / \mathrm{L})$ & $2.06 \pm 0.4$ & $2.10 \pm 0.31$ & 0.757 \\
\hline $\mathrm{P}(\mathrm{mmol} / \mathrm{L})$ & $1.86 \pm 0.59$ & $1.65 \pm 0.44$ & 0.262 \\
\hline TAP (U/L) & $90.32 \pm 76.42$ & $74.45 \pm 33.44$ & 0.500 \\
\hline Vit D (ng /mL) & $15.59 \pm 11.52$ & $16.96 \pm 12.47$ & 0.716 \\
\hline PTH (pg/mL) & $444.38 \pm 401.56$ & $293.24 \pm 110.65$ & 0.010 \\
\hline CRP (mg/L) & $8.03 \pm 12.35$ & $9.09 \pm 11.06$ & 0.75 \\
\hline Albumin (g/L) & $33.99 \pm 8.60$ & $36.32 \pm 6.72$ & 0.391 \\
\hline CTX (ng/mL) & $2.53 \pm 1.53$ & $2.20 \pm 1.43$ & 0.504 \\
\hline bAP (ng/mL) & $27.06 \pm 27.19$ & $25.43 \pm 26.79$ & 0.854 \\
\hline FGF23 (pg/mL) & $221.14 \pm 260.32$ & $226.95 \pm 156.43$ & 0.992 \\
\hline BMD lumbar & $1.150 \pm 0.22$ & $1.130 \pm 0.20$ & 0.740 \\
\hline BMD total hip & $0.859 \pm 0.149$ & $0.814 \pm 0.176$ & 0.356 \\
\hline \multicolumn{4}{|l|}{ Overall } \\
\hline Normal (n (\%)) & $26(32.9)$ & $4(36.4)$ & 0.043 \\
\hline Osteopenia (n (\%)) & $40(50.6)$ & $2(18.2)$ & \\
\hline Osteoporosis (n (\%)) & $13(16.9)$ & $5(45.5)$ & \\
\hline
\end{tabular}

$B M I$ Body mass index, $C a$ Calcium level, $P$ Phosphorus level, TAP Total alkaline phosphatase, vitD $25(\mathrm{OH})$ vitamin $D, P T H$ Parathyroid hormone, BMD Body mass density Significant at $p<0.05$ set in boldface

CTX concentrations are raised in patients with CKD-5D and correlate well with BMD measurements [27]. Moreover, Maeno et al. [26] reported that CTX levels significantly correlate with annual bone loss with sensitivity and specificity at respectively 41 and $83 \%$.

Nevertheless, in another study, serum CTX levels were not different between patients with and without loss of BMD at the distal radius [28].

FGF23 plays an important role in regulating bone mineralization. In our study, FGF23 levels were significantly increased in patients with osteoporosis affecting the lumbar. High FGF23 levels were associated with reduced osteoid thickness in children undergoing dialysis [29]. However, in other studies, BMD was not correlated with serum FGF23 levels [30].

Insufficiency on vitamin D, observed in $41.11 \%$ in our study, is common among dialysis patients [31-35]. There has been much debate about the relationship between vitamin D and BMD. Several studies have demonstrated that low vitamin $\mathrm{D}$ level induced a decrease of cortical BMD in the presumed healthy adult [36]. Our study revealed a positive correlation between vitamin $\mathrm{D}$ levels and femoral BMD.

Fracture rates, observed in $12.1 \%$ in our study, are greatly increased in dialysis patients compared to the 
general population [37]. From our study, it is evident that lower PTH value was associated with an increased risk of osteoporotic fracture. It has been demonstrated that both high and low PTH levels can be associated with a high fracture rate [38, 39].

Another finding of interest in our study is that osteoporotic fractures were associated with the existence of osteoporosis. In a meta-analysis, Jamal et al. suggested that BMD is lower in patients with stage 5 CKD who have fractures [40]. The relationship between BMD measured by DXA and fracture in dialysis patients remains unclear.

There are numerous limitations to our study. First, it is a cross-sectional study. Besides, some other factors which might be associated with osteoporosis such as dosage of heparin and hypogonadism were not studied.

\section{Conclusion}

Our study showed that osteoporosis and fracture are common in patients under dialysis. We highlighted that bone mass loss is the consequence of several factors including age, diabetes and elevated levels of PTH. Osteoporotic fracture risk was associated with the existence of osteoporosis suggesting that DXA measurement is mandatory for the monitoring of bone loss. Our study showed also that both circulating bAP and CTX levels correlated positively with PTH levels. We suggest that bone metabolic markers including BAP and CTX may accurately reflect bone turnover. FGF23 levels were significantly increased in patients with lumbar osteoporosis. Certainly, FGF23 plays a role in the pathogenesis of bone disease in patients with CKD-5D. Other larger longitudinal studies are necessary to codify the assessment of bone disease.

\section{Abbreviations}

25(OH)D: 25(OH) vitamin D; bAP: bone-specific alkaline phosphatase; BMD: Bone mineral density; CKD-5D: Chronic kidney disease on dialysis; CTX: Carboxy-terminal telopeptides of type 1 collagen; DXA: Dual-energy $\mathrm{x}$ ray absorptiometry; FGF23: Fibroblast growth factor 23; PTH: Intact parathyroid hormone; TAP: Total alkaline phosphatase

\section{Acknowledgements}

Not applicable

\section{Authors' contributions}

MS has drafted the work. HS has substantively revised the work. AB has made substantial contributions to the analysis of data. $L L$ has made substantial contributions to the interpretation of data. WS, SR, IG and MS have made substantial contributions to the acquisition of data. FBM has made substantial contributions to the design of the work. ME has approved the submitted version. EC has made substantial contributions to the conception of the work. All authors read and approved the final manuscript.

\section{Funding}

The authors declare that they have no funding for the research.

\section{Availability of data and materials}

The datasets used and/or analysed during the current study are available from the corresponding author on reasonable request.
Ethics approval and consent to participate

Not applicable.

Consent for publication

Not applicable.

\section{Competing interests}

The authors declare that they have no competing interests.

\section{Author details}

'Department of Internal Medicine, Military Hospital, Tunis El Manar University, 1007 Tunis, Tunisia. ${ }^{2}$ Department of Rheumatology, Rabta Hospital, Tunis El Manar University, Tunis, Tunisia. ${ }^{3}$ Department of Clinical, Biochemistry, Pateur Institute, Tunis El Manar University, Tunis, Tunisia. ${ }^{4}$ Department of Immunology, Rabta Hospital, Tunis El Manar University, Tunis, Tunisia. ${ }^{5}$ Department of Nephrology, Rabta Hospital, Tunis El Manar University, Tunis, Tunisia.

Received: 4 April 2019 Accepted: 22 January 2020

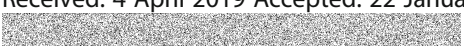

\section{References}

1. Ketteler M, Block GA, Evenepoel P, Fukagawa M, Herzog CA, McCann L, Moe SM, Shroff R, Tonelli MA, Toussaint ND, Vervloet MG, Leonard MB. Diagnosis, evaluation, prevention, and treatment of chronic kidney disease-mineral and bone disorder: synopsis of the kidney disease: improving global outcomes 2017 clinical practice guideline update. Ann Intern Med. 2018;168(6):422-30.

2. Zheng S, Chen Y, Zheng Y, Zhou Z, Li Z. Correlation of serum levels of fibroblast growth factor 23 and Klotho protein levels with bone mineral density in maintenance hemodialysis patients. Eur J Med Res. 2018;23(1):18.

3. Gordon PL, Frassetto LA. Management of Osteoporosis in CKD stages 3 to 5 . Am J Kidney Dis. 2010:55:941-56.

4. Dawson-Hugues B, Mithal A, Bonjour JP, Boonen S, Burckhardt P, Fuleihan GEH, Josse RG, Lips P, Morales-Torres J, Yoshimura N. IOF position statement: vitamin D recommendations for older adults. Osteoporos Int. 2010:21:1151-4

5. Kanis JA, Glüer CC. An update on the diagnosis and assessment of osteoporosis with densitometry. Committee of Scientific Advisors, international Osteoporosis Foundation. Osteoporos Int. 2000;11:192-202.

6. Nickolas TL, Leonard MB, Shane E. Chronic kidney disease and bone fracture: a growing concern. Kidney Int. 2008;74(6):721-31.

7. Taal MW, Masud T, Green D, Cassidy MJ. Risk factors for reduced bone density in haemodialysis patients. Nephrol Dial Transplant. 1999;14:1922-8.

8. Fontaine MA, Albert A, Dubois B, Saint-Remy A, Rorive G. Fracture and bone mineral density in hemodialysis patients. Clin Nephrol. 2000;54:218-26.

9. Ureña P, Bernard-Poenaru O, Ostertag A, Baudoin C, Cohen-Solal M, Cantor T, de Vernejoul MC. Bone mineral density, biochemical markers and skeletal fractures in haemodialysis patients. Nephrol Dial Transplant. 2003;18:2325-31.

10. Yücel AE, Kart-Köseoglu H, Isiklar I, Kuruinci E, Ozdemir FN, Arslan H. Bone mineral density in patients on maintenance hemodialysis and effect of chronic hepatitis C virus infection. Ren Fail. 2004;26:159-64.

11. Mucsi I, Almasi C, Deak G, Marton A, Ambrus C, Berta K, et al. Serum 25(OH)vitamin $\mathrm{D}$ levels and bone metabolism in patients on maintenance hemodialysis. Clin Nephrol. 2005:64:288-94.

12. Petrauskiene V, Petrauskienè $V$, Bumblytè IA, Šileikienè E, Gineikaitè R, Burbulyte R. Evaluation of bone mineral density and its importance for hemodialysis patients. Medicina. 2007:43:90-5.

13. Sit D, Kadiroglu AK, Kayabasi H, Atay AE, Yilmaz Z, Yilmaz ME. Relationship between bone mineral density and biochemical markers of bone turnover in hemodialysis patients. Adv Ther. 2007;24:987-95.

14. Avila M, Prado C, Ventura MJ, Mora C, Briones D, Valdez H, et al. Vitamin D receptor gene, biochemical bone markers and bone mineral density in Mexican women on dialysis. Nephrol Dial Transplant. 2010;25:2259-65.

15. Khan MI, Syed GM, Khan Al, Sirwal IA, Anwar SK, Al-Oufi AR, Balbaid KA. Mean bone mineral density and frequency of occurrence of osteopenia and osteoporosis in patients on hemodialysis: a single-center study. Saudi J Kidney Dis Transpl. 2013:25:38-43.

16. Avramovski P, Sikole A. The progression of bone mineral density loss in Dialysis patients compared with the general population. Korean J Intern Med. 2012;27:436-42. 
17. Toussaint ND, Lau KK, Strauss BJ, Polkinghorne KR, Kerr PG Associations between vascular calcification, arterial stiffness and bone mineral density in chronic kidney disease. Nephrol Dial Transplant. 2008:23:586-93.

18. Malluche HH, Davenport DL, Cantor T, Monier-Faugere MC. Bone mineral density and serum biochemical predictors of bone loss in patients with CKD on dialysis. Clin J Am Soc Nephrol. 2014;9(7):1254-62.

19. Nybo M, Jespersen B, Aarup M, Ejersted C, Hermann AP, Brixen K. Determinants of bone mineral density in patients on haemodialysis or peritoneal dialysis--across-sectional, longitudinal study. Biochem Med. 2013; 23(3):342-50.

20. Valkovsky I, Olsanska R, Tvrdik J, Martinek A, Svagera Z, Pernicova M, Dedochova J, Cermakova Z. Evaluation of biochemical markers and bone mineral density in patients with chronic kidney disease stage 5D at the start of hemodialysis treatment. Biomed Pap Med Fac Univ Palacky Olomouc Czech Repub. 2015;159(1):93-9.

21. Elder GJ, Mackun K. 25-Hydroxyvitamin D Deficiency and Diabetes Predict Reduced BMD in Patients With Chronic Kidney Disease. J Bone Miner Res. 2006:21:1778-84.

22. Souberbielle JP, Roth H, Fouque DP. Parathyroid hormone measurement in CKD. Kidney Int. 2010;77:93-100.

23. Huang GS, Chu TS, Lou MF, Hwang SL, Yang RS. Factors associated with low bone mass in the hemodialysis patients - a cross-sectional correlation study. BMC Musculoskelet Disord. 2009;10:60

24. Lai MN, Hsu IS, Chen YY, Gee MJ, Kao MT. Osteoporosis and associated risk factors for chronic hemodialysis patients. Acta Nephrol. 2002;16:25-30.

25. Okuno S, Inaba M, Kitatani K, Ishimura E, Yamakawa T, Nishizawa Y. Serum levels of C-terminal telopeptide of type I collagen: a useful new marker of cortical bone loss in hemodialysis patients. Osteoporos Int. 2005;16:501-9.

26. Maeno Y, Inaba M, Okuno S, Yamakawa T, Ishimura E, Nishizawa Y. Serum concentrations of cross-linked N-telopeptides of type I collagen: new marker for bone resorption in hemodialysis patients. Clin Chem. 2005:51:2312-7.

27. Herrmann M, Seibel MJ. The amino- and carboxyterminal cross-linked telopeptides of collagen type I, NTX-I and CTX-I: a comparative review. Clin Chim Acta. 2008;393(2):57-75

28. Ueda M, Inaba M, Okuno S, Maeno Y, Ishimura E, Yamakawa T, Nishizawa Y. Serum BAP as the clinically useful marker for predicting BMD reduction in diabetic hemodialysis patients with low PTH. Life Sci. 2005;77:1130-9.

29. Bacchetta J, Cochat P, Salusky IB, Wesseling-Perry K. Uric acid and IGF1 as possible determinants of FGF23 metabolism in children with normal renal function. Pediatr Nephrol. 2012;27:1131-8.

30. Urena Torres P, Friedlander G, de Vernejoul MC, Silve C, Prié D. Bone mass does not correlate with the serum fibroblast growth factor 23 in hemodialysis patients. Kidney Int. 2008;73:102-7.

31. Wolf M, Shah A, Gutierrez O, Ankers E, Monroy M, Tamez H, et al. Vitamin D levels and early mortality among incident hemodialysis patients. Kidney Int. 2007;72:1004-13.

32. Jean $G$, Charra B, Chazot C. Vitamin D deficiency and associated factors in hemodialysis patients. J Ren Nutr. 2008;18:395-9.

33. Seck SM, Cisse MM, Ka EF, Doupa D. Epidemiology of vitamin D deficiency in west African hemodialysis patients: a pilot study from Senegal. Indian J Nephrol. 2014;24:27-128

34. Krassilnikova M, Ostrow K, Bader A, Heeger P, Mehrotra A. Low dietary intake of vitamin $D$ and vitamin $D$ deficiency in hemodialysis patients. J Nephrol Ther. 2014:4. https://doi.org/10.4172/2161-0959.1000166.

35. Drechsler C, Verduijn M, Pilz S, Dekker FW, Krediet RT, Ritz E, et al. Vitamin D status and clinical outcomes in incident dialysis patients: results from the NECOSAD study. Nephrol Dial Transplant. 2011;26:1024-32.

36. Guinota C, Ezzedinec K, Maugera E, Ambroisinea L, Latreillea J, Bertraisd S, et al. Phototype, vitamin D status and bone mineral density among women at risk of osteoporosis. Rev Med Intern. 2006;27:369-74.

37. Pimentel A, Ureña-Torres P, Zillikens MC, Bover J, Cohen-Solal M. Fractures in patients with CKD-diagnosis, treatment, and prevention: a review by members of the European calcified tissue society and the European renal Association of Nephrology Dialysis and Transplantation. Kidney Int. 2017; 92(6):1343-55.

38. Guh JY, Chen HC, Chuang HY, Huang SC, Chien LC, Lai YH. Risk factors and risk for mortality of mild hypoparathyroidism in hemodialysis patients. Am J Kidney Dis. 2002;39:1245-54.
39. Lertdumrongluk P, Lau WL, Park J, Rhee CM, Kovesdy CP, Kalantar-Zadeh K. Impact of age on survival predictability of bone turnover markers in hemodialysis patients. Nephrol Dial Transplant. 2013;28:2535-45.

40. Jamal SA, Hayden JA, Beyene J. Low bone mineral density and fractures in long-term hemodialysis patients: a meta-analysis. Am J Kidney Dis. 2007; 49(5):674-81.

\section{Publisher's Note}

Springer Nature remains neutral with regard to jurisdictional claims in published maps and institutional affiliations.
Ready to submit your research? Choose BMC and benefit from:

- fast, convenient online submission

- thorough peer review by experienced researchers in your field

- rapid publication on acceptance

- support for research data, including large and complex data types

- gold Open Access which fosters wider collaboration and increased citations

- maximum visibility for your research: over $100 \mathrm{M}$ website views per year

At BMC, research is always in progress.

Learn more biomedcentral.com/submissions 